Acta Universitatis Wratislaviensis No 3998

Anglica Wratislaviensia LVIII, Wrocław 2020

https://doi.org/10.19195/0301-7966.58.10

\author{
Marcin Walczyński \\ ORCID: 0000-0001-8666-3603 \\ University of Wrocław \\ marcin.walczynski@uwr.edu.pl
}

\title{
Certified Interpreters' Subjective Experience of Psycho-Affective Factors in Court Interpreting
}

\begin{abstract}
This paper touches upon the theme of the certified interpreter's psycho-affectivity, a construct studied within a branch of interpreting studies known as interpreter psychology, or more precisely, within its psycho-affective strand. What also lays the groundwork for the presentation of the outcomes of the investigation into the certified interpreters' experience of the psycho-affective factors is an overview of certified interpreting. The major part of this paper is dedicated to the discussion of the results of a survey carried out among Polish-English certified interpreters who interpret consecutively in the courtroom. Seven factors experienced by study participants (i.e. anxiety, fear, language inhibition/language ego/language boundaries, extroversion/introversion/ambiversion, self-esteem, motivation and stress) are discussed. The discussion is supplemented with a selection of quotes taken from the certified interpreters' responses, in which they directly or indirectly refer to the selected psycho-affective factors and their impact on the interpreting process and the output rendered. All in all, it emerges that, in quite a number of cases, in the respondents' opinions, the psycho-affective factors under consideration are of a more negative than positive character, thereby disrupting the process of consecutive interpreting in the courtroom.
\end{abstract}

Keywords: certified interpreting, court interpreting, certified interpreter, interpreter psychology, psycho-affective factors

\section{Introduction}

The aim of this paper is to present a study on the psycho-affectivity of Polish-English certified interpreters providing their services in court-related contexts. More precisely, the article attempts to show which psycho-affective factors are experienced by certified interpreters working in the courtroom and how those respondents view the impact the said factors have on their courtroom interpreting performance.

The first part of this article introduces interpreter psychology by concentrating on its psycho-affective strand. What follows is focused on the interpreter's psycho- 
affectivity (constituted by the interpreter's subjectively experienced psycho-affective factors), which is likely to influence the outcome of the interpreting processinterpreting output quality. Then, some brief remarks are made concerning the job of a certified interpreter in Poland. The major part of this paper presents the outcomes of a study carried out among Polish-English certified interpreters performing consecutive interpreting in court-related contexts, in which the certified interpreter's psycho-affectivity is brought to light. Generally speaking, the paper is an attempt to answer questions concerning the self-perceived influence of the certified interpreters' psycho-affective factors on how they render certified interpreting services in the courtroom. One point should be clarified at this stage: although certified interpreting is not identified as a profession as such in Poland, the term certified interpreter is used throughout the paper since this article focuses solely on the activity of interpreting which, under Polish regulations, the certified translator is also obliged to provide.

\section{Interpreter psychology as a subfield of interpreting studies}

Interpreting studies is often viewed as part of translation studies and while this is true because of the many similarities between translation and interpreting, it might be suggested that interpreting studies is gaining more independence and a more specific character. This development of interpreting studies is visible, among others, in the proliferation of various subfields related to different phenomena occurring in the area of interpreting, giving this segment of scholarship a more and more interdisciplinary character (with insights transferred from such fields as anthropology, sociology, technology, psychology or medicine). One such subfield is interpreter psychology, a branch of interpreting studies which tries to account for the psychological phenomena experienced by interpreters while they interpret in various contexts, constellations and settings. Since interpreter psychology accounts for the psychological phenomena which occur in the professional activity of interpreters, it may equally well be subsumed under occupational psychology which, as rightly observed by Christine Doyle (39), "attempts to understand and explain the behaviour and experience of people at work by applying theory and research methods from psychology".

The interests of interpreting scholars in a variety of aspects of interpreter psychology can be safely placed within one of two predominant strands - the cognitive strand and the psycho-affective strand. However, it should be noted that cognition and psycho-affectivity often work together, that "[n]either the cognitive nor the affect- 
ive has the last word, and, indeed, neither can be separated from the other" (Arnold and Brown 1). This view may be further supported by the claim made by Barbara Moser-Mercer, who is of the opinion that both cognition and psycho-affectivity are responsible for the way people perform in their professional and non-professional endeavours. Naturally, this also pertains to interpreters, whose interpreting performance is conditioned by their cognitive capacity and psycho-affectivity.

Of relevance to this paper is the psycho-affective strand of interpreter psychology, which is less abundantly represented in the body of research, with many issues still waiting for more thorough scrutiny. As noticed by Marcin Walczyński (147), "[t]his may result from the common belief that a professional approach to any occupational activity should be devoid of any emotional loads and that such a professional should not show any emotion nor act in an emotional way". Therefore, in comparison to the cognitive dimension of the interpreting process, there is a gap in the understanding of how the interpreter's psycho-affectivity with its constituent elements (i.e. psycho-affective factors) can influence the interpreter himself/herself and the interpreting processes of which he/she is a central figure. While it is true that the first attempts at viewing interpreting as a psychologically conditioned activity were made in the 1930 s (e.g. Sanz), the first rigorous studies on selected aspects of the interpreter's psycho-affectivity were conducted in the 1990s. A good case in point is the attempt at constructing a trainee interpreter's psycholinguistic profile (Brisau, Godijns, and Meuleman), in which, among others, such psycho-affective concepts as self-concept, anxiety, language ego, motivation or stress resistance were referred to. Soon afterwards, more attention started to be drawn to the themes of the interpreter's psycho-affectivity, since it was found that interpreters experience various difficulties and some of them may be directly linked to their management of psycho-affective factors (e.g. Mead; Valero-Garcés; Bontempo and Napier). Other scholars (e.g. Timarová and Ungoed-Thomas; Timarová and Salaets) also made some references to psycho-affectivity while discussing interpreting training, in particular, testing aptitude for interpreting. Moreover, the fact that the interpreter's psycho-affectivity has begun to be given more emphasis is also visible in Betty Colonomos' proposal of the Integrated Model of Interpreting, in which the psychological factors are given some prominence. Recently, more studies revolving around such psycho-affective themes as stress (e.g. Korpal) or psycho-affective factors (e.g. Walczyński) have been published, which shows that this strand of interpreter psychology is gaining more and more significance as a legitimate object of scholarly inquiry and this, in turn, proves that professionalism in interpreting does not have to mean psycho-affective neutrality since, as is presented in the following sections, interpreters often experience a variety of psycho-affective factors which affect their interpreting performance. 


\section{Psycho-affectivity in interpreting: psycho-affective factors and their impact on interpreting quality}

The activity of interpreting is naturally a cognitive task, since it requires the activation of such cognitive processes as comprehension, processing and memorization, to name but a few. However, it also turns out that interpreting, viewed as a social act of interlinguistic communication between at least two different parties through the agency of the interpreter, is also a psycho-affectively involving task. In other words, while providing interpreting services, the interpreter exhibits traits of his/her psycho-affectivity - a set of the interpreter's individual intrinsic psychological properties; his/her psychological makeup. What is more, the interpreter's psycho-affectivity is directly related to a variety of mechanisms allowing him/her to manage the influence which psycho-affective factors may exert on the interpreter himself/herself and, ultimately, on the quality of the interpreting process outcome - the output. As regards the aforementioned psycho-affective factors, Walczyński (155) thinks that:

"psycho-affective factors" can be understood as "individual personality traits" (Arnold, Brown 1999: 8) which are characteristic of an individual interpreter and therefore whose activity may vary from person to person (and that is why they are sometimes referred to as "psycho-affective variables").

Based on the above-quoted definition, it may therefore be stated that the psycho-affective factors are the internal properties of the interpreter which determine the interpreter's psychological responses to various stimuli. They are all related to how interpreters see themselves as both people and professionals, how they evaluate their skills, knowledge and competences as well as how they view other people participating in the process of interpreting. The psycho-affective factors are an essential element of what may be known as the psycho-affective sequence-the path in which other elements of the interpreting process activate the psycho-affective factors and in which those factors trigger other components in this sequence. It seems that psycho-affective factors can be arranged in a five-element psycho-affective sequence, with a stimulus, the interpreter's bodily reactions, the interpreter's (verbal and non-verbal) behaviours and other factors (i.e. the cognitive ones) (cf. Gorman 5; Walczyński 158). There are various interrelations among those five components, which shows that one component may activate as well as be activated by another. Interestingly enough, the entire psycho-affective sequence may proceed differently among different interpreters, with different stimuli, different levels of the subjective experience of psycho-affective factors, different bodily reactions or different behaviours. This may also corroborate the statement that all people are different in terms of their psycho-affectivity and that is why what induces the activation of one psycho-affective factor which has a negative effect on one interpreter may impact positively on another interpreter. This also justifies another legitimate name which is sometimes used with reference to these factors-individual psycho-affective factors. 
In this study, the certified interpreters' subjective experience of seven psychoaffective factors (most frequently studied within applied linguistics) was examined: anxiety, fear, language inhibition/language ego/language boundaries, extroversion/introversion/ambiversion, self-esteem, motivation and stress.

As regards anxiety, it may be defined as a state of uneasiness, apprehension and worry induced by a person's negative thinking about a subjectively viewed negative event. Interpreters may often experience this psycho-affective factor for the simple reason that they may perceive the very act of interpreting as an adverse event likely to expose their deficits. Following occupational psychologists, interpreting scholars dealing with interpreter psychology distinguish several types of anxiety which can manifest themselves in the practice of interpreting. There is facilitative/beneficial anxiety, which helps the interpreter to perform better, and debilitative/inhibitory anxiety, which lowers his/her ability to cope with an interpreting task. There is archaic anxiety, related to past events, and there is existential anxiety, related more to present and future events. An interesting subtype of existential anxiety (apart from acceptance anxiety and orientation anxiety) is performance anxietythe anxious feelings related to the interpreter's skills, competences and knowledge and the (in)ability to cope with an interpreting task ( $c f$. Heron, Piechurska-Kuciel).

Albeit commonly confused with anxiety, fear has a different background, since its experience is triggered by an objective threat existing in the real world. Moreover, it may be stated that not only humans react to fear, because other living species also respond to it. For this reason, it may be explained as "the affect of a motivational system that attempts to protect an organism from physical harm or destruction" (Jones 100). However, the experience of fear among interpreters is rather rare and when it occurs, it is usually related to interpreting in dangerous situations (e.g. during wars or in other conflict zones).

Language ego, along with language boundaries and language inhibition, constitutes another psycho-affective factor that has been studied. This originates from the interpreter's perception of his/her linguistic competence and the resulting (un)willingness to use some language forms. If the interpreter realizes that he/she has not fully internalized some elements of language, be it grammatical structures or some specialized lexical items, he/she may not be willing to risk using the incorrect versions of those constructions/lexemes for fear of making mistakes which could endanger the interpreter's language ego. In this way, language ego becomes weaker, language boundaries grow stronger and language inhibition develops.

Extroversion, introversion and ambiversion as three general dimensions of personality - another psycho-affective factor-are also at times said to be responsible for the way in which the interpreter handles a given interpreting task. Each dimension may be characterized by a set of properties (e.g. seeking the source of positive emotions externally or seeking them internally, i.e. within oneself; gregariousness or reclusiveness, talkativeness or taciturnity) which manifest themselves in a person's private as well as professional life. Some of these attributes like, for 
instance, sociability or verbosity, which are commonly associated with extroversion, can, therefore, predispose a person towards interpreting which is, in fact, a bilingual communicative speaking activity. Such a view is expressed by, among others, Alessandro Zannirato, who contends that extroversion, progressiveness and high levels of achievement motivation are those properties which characterize competent interpreters. However, it is often ambiversion that interpreters can be characterized by, since it is a dimension combining some features of the extrovert and the introvert. Moreover, it turns out that personality dimensions, in particular introversion, do not have to be reflected in the interpreter's professional activity, for introverted people are capable of disguising their real personality dimension by what is known as the persona or the public self(e.g. Silverman).

Self-esteem is another component of the interpreter's psycho-affectivity which was examined with reference to Polish-English certified interpreters. It is viewed as the interpreter's own perception and evaluation of himself/herself and his/her own skills as well as the circumstances in which he/she happens to work (including other people and the environment). Stanley Coopersmith, perhaps one of the first scholars to study the concept of self-esteem, claims that "self-esteem is a personal judgement of worthiness that is expressed in the attitudes that the individual holds towards himself" (Coopersmith 5). Because of the aspect of self-evaluation, selfesteem (or its high/positive, neutral and low/negative levels) may be categorized as global/general self-esteem (the general view people hold of themselves), situational self-esteem (the situation-related view people hold of themselves) and task self-esteem (the task-related view people hold of themselves). Another category is intermediate self-esteem, which may be defined as the view people hold of themselves with reference to particular competences or skills (i.e. interpreting self-esteem).

Motivation or, more precisely, achievement motivation - another psycho-affective factor which is studied - may be defined as a source of the drives making the interpreter want to perform interpreting. Such sources may be internal, i.e. resulting from the interpreter's own internal needs and interests, and then it is regarded as internal/intrinsic motivation, or external, i.e. resulting from some reward waiting for the interpreter in the external world (e.g. remuneration, a positive reputation etc.), in which case external/extrinsic motivation comes to the fore. Needless to say, in their professional activities, interpreters at large are driven by both types of motivation.

The final element analyzed in the study is stress. In fact, this is not a psychoaffective factor in a strict sense, but rather a phenomenon frequently experienced by interpreters which may be defined as a variety of psychological and physiological responses to the stimuli present during the interpreting process. Moreover, its occurrence can also be presented in the form of the psycho-affective sequence discussed above. Stress can be induced by nearly all elements of the interpreting process and can influence virtually all of the components of this process. Generally speaking, there are two types of stress: eustress, the positive type which motivates 
and facilitates the interpreter's performance, and distress, the negative type which may hinder interpreting by adversely affecting the interpreter's skills and cognitive capacity (Riccardi). It seems that stress is the most comprehensively examined psycho-affective factor experienced by interpreters, since there have been many projects analyzing different aspects of stress and the manners in which it affects interpreting quality (e.g. Korpal, Kurz).

On the whole, the preliminary findings related to the interpreter's psycho-affectivity confirm that interpreters' experience of psycho-affective factors may result from different stimuli and may have various consequences (sometimes positive, sometimes negative) for the quality of the output rendered. It remains to be seen in the further part of this article in what way Polish-English certified interpreters' psycho-affectivity impacts on their certified interpreting performance.

\section{Certified interpreting in Poland: preliminaries}

Certified interpreting ${ }^{1}$ is a type of interpreting practised by professionals whose high qualifications have been positively verified in the course of a state examination in both translation and interpreting administered by the Polish State Examination Board in Poland's Ministry of Justice. The fact that the testing procedure is difficult and naturally psycho-affectively engaging can be corroborated by the success/failure data collected by Bolesław Cieślik (7) who claims that:

The certified translation examination is very difficult and therefore the pass rate does not exceed $25 \%$. The aim of this examination is to verify the qualifications of individuals, on whose skills other people's property, freedom or the right to stay in the Republic of Poland can rely. In this way, only the best candidates can become certified translators. ${ }^{2}$

The presence of a certified interpreter is required in some specific formal, mostly law-related, contexts in which speakers of different languages participate. Among such situations are, for instance, bilingual weddings, bilingual activities in the notary's office such as signing contracts or opening wills or testaments, police interrogations or courtroom interactions. Since many of those situations are negative emotion-laden and include sensitive contexts, the practice of certified interpreting is quite often linked with the certified interpreter's experience of various psycho-affective factors, of which perhaps the most common are stress and anxiety. However, there have been few studies linking the psychological aspects

${ }^{1}$ In Poland, certified translators are also obliged to perform certified interpreting. There is no formal distinction between certified translators and certified interpreters and to obtain the status of a certified translator, a candidate has to pass the certified translation and interpreting examination. However, because this article is dedicated to the psycho-affective factors in interpreting, the designations certified interpreting and certified interpreters are consistently used throughout this paper, with little reference to certified translation or certified translators.

2 Translated from Polish by M. W. 
of interpreting with the practice of certified interpreting and therefore this study may be a contribution to the development of this yet not fully explored area of interpreting studies.

Certified interpreting can be performed in a variety of forms, of which the most common are consecutive interpreting and sight translation/interpreting. Of particular interest in this paper is the former type, since consecutive interpreting is the most predominant mode used in Polish courts, where courtrooms are not equipped with simultaneous interpretation booths which would expedite the communication interactions between the parties involved and, perhaps, the entire court proceedings. For this reason, certified interpreters interpret mostly consecutively, from and into A and B languages, the dialogues uttered in the courtroom. At times, in the case of longer monological utterances, certified interpreters may find it easier to take notes in the listening phase and then to render the output on the basis of the information noted.

As mentioned above, the context of a courtroom, in which the certified interpreter has to mediate linguistically between the parties (e.g. judge, respondents, defendants and their legal representatives) and enable them to communicate successfully, turns out to be psycho-affectively engaging, since there are at least several aspects which are likely to activate the certified interpreter's experience of psychoaffective factors, because of which the quality of the interpretation rendered may suffer. In the next sections of this paper, those issues are presented.

In general, certified interpreting is a profession which requires not only interpreting and linguistic skills, but also at least some orientation in legal issues, familiarity with legal terminology and acquaintance with the ways of behaving in court-related contexts. However, there is a significant barrier to this professionthe challenging testing procedure, which discourages many interpreters from this occupation. Therefore, only a handful of candidates become certified interpreters.

\section{Certified interpreters' psycho-affective factors in court interpreting}

This study is a small fragment of a large-scale research project devoted to the examination of trainee interpreters' and Polish-English certified interpreters' subjective experience of psycho-affective factors (Walczyński). However, for this paper, only the data concerning courtroom transactions and their relation to certified interpreters' psycho-affectivity were extracted from the research data corpus. The following sections present the rationale for studying certified interpreters' psychoaffectivity in the context of courtroom communication, the study's methodological foundations and outcomes. 
4.1. The rationale for studying certified interpreters' psycho-affectivity

It is general knowledge that in the majority of activities which humans undertake, people experience some affects - attitudes, feelings or emotional states. Interpreting at large and certified interpreting are no exception.

Due to the specific nature of courtroom communication, with the frequently visible imbalance of power among the parties involved (the judge $v s$ respondents and defendants; respondents' and defendants' barristers/attorneys-at-law $v s$ defendants and respondents; the state $v s$ the individual) and the position of a certified interpreter, which may be inappropriately or not fully-recognized, the certified interpreter is frequently made to work in a psycho-affectively demanding environment in which his/her psycho-affectivity is regularly activated and impacts on the interpreter, as well as on the quality of the output rendered. For this reason, it seems justified to take a closer look at why the courtroom constitutes such a psycho-affectively challenging environment, which elements of the certified interpreting process are responsible for the certified interpreter's psycho-affective factors and what consequences, in the certified interpreters' opinions, they may have for target text production.

\subsection{The methodological foundations of the study}

The study, of which this paper presents just a small fragment, was carried out in the form of a survey in July/August 2018 among a sample of 76 Polish-English certified interpreters providing their services in Poland. The questionnaire survey, which was composed of 46 factual, behavioural and attitudinal questions, was available online on a special study-dedicated website-https://afektywnosctlumacza. webankieta.pl/.

As mentioned above, the data concerning the relations between courtroom transactions and certified interpreters' psycho-affectivity was extracted for this article from the collection of raw data and analyzed with the use of qualitative paradigm methods (i.e. the observational methods, the narrative method, and the direct quotation method). The descriptive statistics method was used only to bring certain quantitative data to light. The data is presented in the form of a narrative report which is frequently supplemented by anonymized quotes ${ }^{3}$ derived from the study respondents' replies to the questionnaire's questions. The goal of such a presentation is to let the certified interpreters speak for themselves. Finally, some general trends are highlighted.

At this point, one methodological remark must be made. Since, as mentioned above, the study discussed in this paper presents a fragment of a large-scale research project on consecutive trainee interpreters' and certified interpreters' psycho-af-

\footnotetext{
3 Originally in Polish, the quotes were translated into English by M. W.
} 
fective factors, the relevant quotes included in this article have been borrowed from the chapter entitled "Case study 4-certified interpreters' subjective experience of the psycho-affective factors in consecutive interpreting" (Walczyński 455-551).

\subsection{Study results}

Before the presentation of behavioural (i.e. related to the certified interpreters' behaviours) and attitudinal (i.e. the views concerning the certified interpreters' attitudes and opinions) information, let us take a look at some of the factual data which may partially account for why the above-presented psycho-affective factors may become activated during certified interpreting. The first set of data is related to the study participants' gender, age and experience. As regards the first criterion, there were 55 women $(72 \%)$ and 21 men (28\%). The average age was 46 . The youngest respondent was 29 ( 1 person) and the oldest was 74 (1 person). On the basis of this age range, it may be stated that in the majority of cases, the profession of a certified interpreter is practised by rather mature people, with some life experience in dealing with their psycho-affectivity. However, because of the specific nature of certified interpreting, it is worth analyzing the number of years of experience in providing consecutive interpreting services. Generally speaking, the average number of years of consecutive interpreting experience was 16.51 certified interpreters $(67 \%)$ participating in the study had more than 10 years of experience and 3 respondents had practised this mode of interpreting for no longer than 3 years. On the basis of this set of data, it might be speculated that the certified interpreters were experienced in consecutive interpreting and that, because of their age and life experience, they might have developed some individual psycho-affective tactics which helped them to counteract the negative impact of their psycho-affective factors. However, what can also determine the manners in which the certified interpreters deal with their psycho-affectivity manifesting itself during court interpreting is the frequency of interpreting consecutively in court-related contexts. Only 6 respondents $(8 \%)$ declared that they perform certified consecutive interpreting very often (several times a week). 19 certified interpreters $(25 \%)$ do it often (several times a month) whereas others (23 respondents-30\%) interpret consecutively in settings requiring certification either rarely (once/twice a month) or very rarely (several times a year) - 28 certified interpreters (37\%). The fact that two-thirds of the sample practise certified consecutive interpreting rarely can also account for the problems which the respondents had with the impact of their psycho-affective factors during courtroom interpreting.

Out of 76 certified interpreters who provided their responses to the questionnaire, $62(82 \%)$ declared that they perform courtroom interpreting and for that reason only the responses of those respondents were subjected to further analysis. However, the most common type of certified consecutive interpreting is that in the notary's office ( 72 certified interpreters, $95 \%$ ). What is also interesting is that 
courtroom interpreting was the most common type of interpreting performed for only 20 respondents $(26 \%)$. The outcome of the factual data analysis proves that legal contexts are the most common settings in which Polish-English certified interpreters are employed. Those contexts (especially the courtroom) are also known to be psycho-affectively demanding and that is why they are often related to some emotional burden and the activity of psycho-affective factors.

When asked about their general affects (i.e. emotions and feelings) before the certified consecutive task in the courtroom, the respondents enumerated both positive and negative feelings. Among the most commonly selected feelings were: curiosity (53\%), stress (50\%), insecurity (43\%), composure (38\%), anxiety $(16 \%)$. The positive feelings, such as curiosity or composure, typically emerge from the certified interpreters' extensive knowledge and skills as well as their internal need for dealing with interesting and new themes. However, rarely do the respondents experience positive emotions in relation to courtroom interpreting (unlike interpreting in a notary's office, which has more positive psycho-affective associations). The following two quotes illustrate this:

- Court proceedings which I interpret are usually interesting. Besides, this is an adventure.

- I know court proceedings and I know what happens in the courtroom. I am interested in what the trial today will be like.

Among the negative feelings experienced prior to the certified interpreting task are those related to the certified interpreters themselves, in particular to some psycho-affective factors, such as lowered levels of intermediate self-esteem and performance anxiety. Moreover, the negative feelings are also related to the fact that the certified interpreters have no possibility of preparing for courtroom interpreting since, for instance, the court does not grant access to the documents used in the proceedings. Several citations bring those aspects to light:

- I don't know what I can expect, whether there will be some vocabulary I am unfamiliar with. It sometimes happens that I know only the subject matter of the proceedings and only when in the courtroom do I get information about the details. The court does not give prior access to the documents which enable the interpreter to prepare for interpretation.

- It is true that I can prepare for the subject matter of the trial, but it is not possible to prepare for interpreting for a person who speaks nervously, unclearly or - to put it simply — who knows the language at a low level.

- Sometimes in the course of a court case, some unexpected terminology occurs (e.g. in a case for damages, where I was told to be prepared for discussing the financial aspects of paying the damages, the case unexpectedly turned to discussing skin transplants and medical complexity). But I have to admit that this does not stress me nor paralyzes me; it is an intellectual challenge which I have always met.

- Sometimes there is the unfamiliarity with the subject (the court/another party/the client does not want to show the files or, peculiarly, insists on confidentiality without realizing that the more I know, the more quickly and efficiently I will interpret).

Another source of the negative feelings subjectively experienced by the respondents is the human factor. It means that other participants of court proceedings 
are likely to evoke negative emotions and thinking among the certified interpreters. What is particularly clearly visible is the power imbalance, in which the certified interpreter is not properly respected by the judge or the parties' representatives, even though without the figure of the certified interpreter the proceedings could not be continued. Sometimes, the respondents wrote about unjustified criticism of their interpreting skills and the parties' aggression aroused by the interpreter's work. Those reservations are raised in the following quotes:

- I am an introvert, and interpreting is a great effort for me. I'm stressed that for some reason I will not be able to do the job. I also had an unpleasant experience with interpretation in court (I was criticized by the judge for not wanting to interpret her statements word-for-word instead of summarizing the sense for the lost foreigner). Generally, I try to avoid this kind of work as much as I can. I feel much better in translation.

- I associate the negative feelings mostly with courts because of the high level of stress (for all the people present), stringent requirements, within which I do not really feel confident (the flowery speeches of attorneys, the domain issues - legal issues, where you can stand, when you can speak). Sometimes there is an audio- and video-recording of the interpreting performed and at times this is totally without preparation when the court denies access to the files. And, at the end, several months of waiting for very meagre remuneration.

- Sometimes negative feelings arise from the client's attitude. They demonstrate it by saying "we all speak English and actually you are not needed here", by cutting in with their knowledge or by correcting me (as illustrated by one case going on for a year in which I have been interpreting: one of the plaintiffs is convinced of his linguistic knowledge to such an extent that he interrupts the judge, for which he has received many reprimands).

- Stress - in courtroom interpreting - the topic is often difficult, especially in the area of economics. One needs to be knowledgeable about the matter to interpret it well. Accuracy of interpreting is also of great importance, including the proper selection of words. It happens that the parties' barristers pick on particular phrases, trying to force their versions and interpretations. Moreover, they also use this rather artificial language (legalese) and I have the impression that their aim is to make the matter maximally complicated. Generally, the judge usually speaks simply and clearly and the barrister - strangely, using such phrases as "Czy był Pan w przekonaniu...?" ["Have you been of the conviction...?"].

- The courtroom and the police-you never know what to expect. The other party in courts is often aggressive and claims that the interpreter interprets wrongly.

- The suspicion of the aggressive attitude of one of the parties.

The above quotes show that there are more reasons for negativity before certified interpreting in the courtroom than there are for positive attitudes. It seems that courtroom settings, with its actors (the judge, parties, parties' representatives), are highly likely to evoke negative feelings. Likewise, certified interpreters' own beliefs and attitudes towards their overall interpreting competence can also be held responsible for there being so much negativity even before the work of courtroom certified interpreters starts. Let us now focus on the certified interpreters' subjective experience of each of the psycho-affective factors presented above and their linguistic and non-linguistic exponents.

The first psycho-affective factor to be analyzed is anxiety, which is experienced by 42 certified interpreters $(68 \%)$. Of course, those certified interpreters who perform 
consecutive interpreting rarely or very rarely declare that they experience anxiety more often (33 respondents in total, 53\%) whereas those who work in courtrooms more frequently (i.e. often and very often) are less anxious ( 9 certified interpreters in total, $15 \%$ ). This can be easily correlated with greater experience: the more experience the certified interpreters have in certified consecutive interpreting, the less likely they are to experience anxiety. The reasons for the experience of various types of anxiety (i.e. archaic anxiety and the subtypes of existential anxietyorientation anxiety, acceptance anxiety and performance anxiety) during courtroom interpreting are manifold. Sometimes they are related to the certified interpreter's past courtroom interpreting experience, sometimes to their thinking about their interpreting competence. The following quotes illustrate this:

- Fear of being suspected of having an insufficient level of competence.

- Fear of criticism, fear of making a mistake, fear of a situation in which I will not know how to interpret.

- Feeling unwell, for example, when I had to interpret for 5 hours in court immediately after suffering from inflammation of the larynx, still weakened and coughing...

- Uncertainty whether I will remember everything, whether I can keep up.

As observed by these respondents, the experience of anxiety can result in errors (i.e. linguistic exponents) in pronunciation, grammar, lexical choices or equivalence disturbances. Similarly, those certified interpreters' non-linguistic behaviours and bodily reactions may be determined by anxiety. Among the most common nonlinguistic exponents are body tension, sweating, increased gesticulation or accelerated heartbeat. They often go together. Moreover, because the psycho-affective sequence may involve several psycho-affective factors at a time, the linguistic and non-linguistic exponents can be attributed to those several elements of the certified interpreter's psycho-affectivity and for this reason, statements concerning the potential exponents should be treated cautiously. Generally speaking, the setting of the courtroom may account (at least to some extent) for the certified interpreters' experiencing various types of anxiety.

Another psycho-affective factor is fear. As mentioned earlier, because of its nature and origin, it was not expected to be found among the certified interpreters. However, it appears that some levels of fear are also experienced by 17 certified interpreters $(27 \%)$ working in the courtroom. In the majority of cases, the respondents could indeed have experienced fear caused by the presence of aggressive and threatening people.

- Abnormal behaviour of the participants in the trial. It has happened to me twice during my work.

- Aggression of "the other party" in the courtroom.

- Once I happened to perform interpreting in a criminal case, in which I was afraid of the accused and sat next to him (interpreting for him) for a long time. Besides this event, I have not experienced fear.

- The very aggressive attitude of a suspect who was suspected of serious crimes. 
The linguistic and non-linguistic exponents of fear among those certified interpreters who happened to work in court proceedings in the presence of aggressive participants or those behaving abnormally included, among others, equivalence disturbances (i.e. omissions), lexical errors or pronunciation errors as well as body tension, sweating, a dry throat or an accelerated heartbeat. On the whole, although theoretically fear should not be a psycho-affective factor adversely affecting the certified interpreters' performance in the courtroom, it at times does so by the mere fact that suspects or the accused may pose a real threat.

Let us now take a look at the certified interpreters' language ego and the resulting language boundaries and language inhibition. As has already been pointed out in the section on the respondents' experience of anxiety, language inhibition does occur. As many as 42 certified interpreters (68\%) report this psycho-affective factor and, as in the case of anxiety, it is more pervasive among the less experienced certified interpreters who perform consecutive interpreters less frequently.

As regards the causes of the subjective experience of language inhibition, there were few references to court-related contexts, so it is difficult to pinpoint how this factor can be directly linked to the practice of court interpreting. However, the following quotes accentuate that the context of the court may be at least partially responsible for inhibition:

- Digressing onto the topics belonging to the areas in which I do not specialize, for instance, in the description of accident injuries during a court trial.

- The behaviour of the participants in the trial.

- When a native English person tries to show that the certified interpreter does not understand the slang word used in his village in County $\mathrm{X}$ and shows in the courtroom that, for example, the funeral meal is known as a "weeght"/."wake" etc.

Among other reasons for language inhibition, the certified interpreters usually pointed to their other psycho-affective factors like lower levels of self-esteem concerning their interpreting and linguistic skills (i.e. intermediate self-esteem), anxiety or stress. Inhibition manifests itself in the linguistic dimension of the certified interpreting act, during which the inhibited certified interpreters tend to use less advanced grammatical and lexical structures or omit input information because of source text incomprehension. As far as the former linguistic exponent is concerned, it may be justified by the certified interpreters' awareness of the fact that any mistake can alter the original meaning and thus influence the course of court proceedings. One certified interpreter made this clear in the following excerpt:

— I do not risk making a mistake, I use simpler wording, especially in the courtroom, where the interpreter's mistake can have enormous consequences.

To hide this, the respondents sometimes used the explicitation strategy-constructing a target text that is longer and more information-laden than the source text. The non-linguistic exponents again overlap with those reported for anxiety.

On the whole, although language inhibition is rather a strong psycho-affective factor, the respondents did not mention courtroom settings as being those which 
particularly increased the occurrence of this element of the certified interpreters' psycho-affectivity and among the reasons intensifying the experience of language inhibition are only the behaviour of other participants in court proceedings or some references that are not to the point. It might be concluded that inhibition does not only occur in courtroom settings, but it is a more general psycho-affective response ensuing from the certified interpreters' beliefs and attitudes towards their overall consecutive interpreting competence.

Another factor that was studied is extroversion/introversion/ambiversion. 47 respondents $(76 \%)$ see the relationship between their personality and certified interpreting. What this implies is that the personality type which the certified interpreters can be characterized by may, at least to some extent, determine the ways in which they practise their profession. Based on some characteristic properties of each personality type, the certified interpreters were requested to determine which personality type they felt they had, and what emerged from this self-evaluation is that there were generally 20 extrovert respondents (33\%), 17 introvert certified interpreters (27\%) and the remaining $25(40 \%)$ were ambiverts. Generally speaking, the results are in line with the common assumptions that introversion is the least preferred personality type, whereas extroversion is the most favourable dimension. However, it is ambiversion by which many respondents can be represented.

When asked about the ways in which personality manifests itself in the certified interpreters' work in the courtroom, many extroverts stated that the use of the strategy of explicitation was predominant. This was also linked to their increased verbal expression. The introverted certified interpreters were of the opinion that their personality led to faithful interpretation without any additional remarks. Many ambiverts were also more explicit but, on the whole, their personality did not influence their interpreting to a significant extent. Unfortunately, the respondents did not write much about the relationship between their personality and certified court interpreting. This may result from the fact that they share the view that courtroom interpreting does not allow them to exhibit their personality traits because of its highly formalized frameworks.

Interestingly enough, the certified interpreters' extroversion is visible not so much in the linguistic indicators, but rather in the non-linguistic exponents. Among them are, for example, the willingness to engage in interaction in the courtroom and the willingness to help. Although again the respondents did not focus on courtroom interpreting in their responses, it might be postulated that because of this, seeing the power imbalance, they tend to align more with the weaker parties in the courtroom. The introverted respondents wrote about neutrality and a tendency to have little interaction with the participants in the certified interpreting act. However, the study of personality types in the context of certified court interpreting also revealed that in several cases the respondents were well aware of their public personae- the disguise personality which they assume when practising consecutive interpreting. It might, therefore, be posited that to some extent personality may be responsible 
for the way the certified interpreters perform consecutive interpreting, but it is by no means possible to determine the details of this influence. Hence, only the tentative conclusion can be drawn that the extroverted certified interpreters may find it easier and more comfortable to work in the courtroom, while the introverts may think the opposite.

Self-esteem is yet another psycho-affective factor whose impact was studied with reference to the certified interpreters participating in the study. 50 respondents $(80 \%)$ admitted to having experienced this psycho-affective factor in their professional endeavours. From among several types of self-esteem, two of them-the general/global one and the intermediate one (i.e. related to interpreting competence made up of, among others, interpreting subcompetence and linguistic subcompetence) were examined. As regards the former type, 33 certified respondents in total $(53 \%)$ declared high and very high levels of general self-esteem, the average (neutral) level was attested by 23 respondents (37\%), whereas 6 certified interpreters $(10 \%)$ claimed to have low levels of general self-esteem. In the case of interpreting subcompetence-related intermediate self-esteem levels, they are distributed in the following way: high and very high self-esteem - 36 respondents (58\%), average - 18 certified interpreters (29\%) and low and very low-8 interpreters (13\%). Linguistic subcompetence-related intermediate self-esteem levels were indicated in a slightly different way: very high and high levels - 44 certified interpreters in total (71\%), average level -17 respondents $(28 \%)$ and low -1 certified interpreter $(1 \%)$. What is surprising is that still a relatively large number of the certified interpreters defined their self-esteem associated with their linguistic and interpreting subcompetences as low, especially in view of the fact that many of them had successfully undergone the difficult testing procedure confirming their high linguistic and interpreting skills. Perhaps one of the reasons for this situation is the fact that rarely do they interpret consecutively and another point is the influence of other psycho-affective factors, with anxiety and stress being the most pervasive. Regrettably, the respondents did not provide a wealth of information concerning their levels of self-esteem or their linguistic and extra-linguistic manifestations in courtroom interpreting. Court contexts were mentioned only in passing, such as the one concerning the certified interpreter's sitting/standing position while interpreting provided below:

- The position depends on the conditions: I sit at the police station, in the courtroom-I sit when interpreting for the party, and I stand when interpreting for the court. I usually have a notebook and a pen to take notes, but it also helps me as it gives me something to do with my hands, I avoid excessive gestures.

Generally speaking, it seems that self-esteem is a psycho-affective factor that does not have a particularly adverse influence in court-related contexts, since the courtroom is rarely mentioned as a circumstance which could reveal the influence of this factor on the overall quality of court interpreting. This finding is in line with the general conclusion drawn from the study of the certified interpreter's self-es- 
teem which holds that "this psycho-affective factor seems not to have a definitely negative impact on the quality of the certified interpreters' performance since the levels of the studied types of self-esteem are generally positive" (Walczyński 520).

Let us now take a look at motivation as another psycho-affective factor which could potentially influence the way in which the certified interpreters perform their job. It turns out that the majority of the certified interpreters (56 individuals, $90 \%$ ) participating in the study are motivated during certified interpretation. The primary source of motivation identified among the respondents was an intrinsic one, mostly the internal need for providing high-quality services, which can equal professionalism in this occupation. The following quotes can shed some light on this type of motivation:

- Drawing pleasure from the very act of internally located striving to satisfy an internal norm related to the quality of work.

- I want to behave professionally and be perceived as such.

- I want to interpret as best as I can as it is my profession. I want to help. I want to do what I love, that is, to interpret, and it is crucial for me to be the mirror in which the text is reflected. I do not have such high external motivation - money is far behind.

- The need to do the job flawlessly, not giving the lawyers the argument that "my client lost the case because the interpreter was bad and interpreted badly", since some colleagues have had to struggle with such accusations.

Among other internal motivators are helping people, meeting professional challenges, achieving public recognition and building a reputation. However, in the corpus there were no direct references to court interpreting and those internal motivators.

External motivation was also found to condition, at least to some extent, the certified interpreters' work. There were two basic motivating forces of an external nature: the fulfilment of the statutory obligation to perform certified interpreting, and remuneration (however, not in the courtroom context). As regards the latter, it is worth quoting two responses, in which their authors directly state that courtroom interpreting is not well rewarded and that this demotivates them:

- I like this job and - apart from courtroom settings - I get a good salary. I am a professional, I like to quickly and efficiently execute orders, work in difficult and new projects, I am happy with the positive response of my clients - their praise gives me a boost and makes me willing to work.

- Professionalism, statutory obligation, remuneration (not in the case of courts), reputation in the environment.

In the majority of cases, the certified interpreters claim that motivation is a psycho-affective factor which usually has a positive impact on their performance. They think that motivation makes them pay more attention to language correctness, equivalence or appropriateness. They also state that motivation, especially the internal kind, helps them be professional, neutral (as far as possible), reliable and ethical.

Since for so many respondents motivation turned out to be of a facilitative nature, it is perhaps one of few positive psycho-affective factors (next to extroversion 
and self-esteem). Other factors presented so far have usually - in the respondents' opinions - turned out to be of a more debilitative than facilitative character.

The final factor which needs a brief analysis is stress, which is known to be omnipresent in interpreting. Because of its formality, some kind of stiffness and the visible imbalance of power, court setting interpreting typically induces considerable stress among the certified interpreters, since 52 of them (84\%) declared their subjective experience of this factor. However, this experience may be of a threefold nature: it may be debilitative (19 respondents, 31\%), it may be neutral (17 responses, $27 \%$ ) and it may be facilitative (26 respondents, $42 \%$ ).

Among the stressors are those related to court settings like, for instance, unfamiliarity with specific law-related concepts raised during court proceedings, other participants in the certified interpreting act (e.g. judge, parties, parties' legal representatives) and their behaviours:

- Court, subject matter, the behaviour of other people.

- Court/police: judge's/client's lack of cooperation (speaking too fast), awareness of responsibility for my words.

- Court: the presence of specific persons.

- During court interpretations, lack of familiarity with some concepts; in the case of other interpretations, lack of familiarity with the processes (e.g. financial).

- Issues from other fields of knowledge than those previously announced that appear unexpectedly (e.g. the civil case concerns compensation for complicated medical complications).

- Representatives of the authorities, the subject matter of the interpretation.

- The behaviour of other people, a lack of understanding of the character of our profession.

- The blatant behaviour of the court accounting department and the practice of some judges and registrars to give as little remuneration as possible or nothing at all; the interpreter should come to the court at her own expense and the invoice for the service is paid half a year later.

- The context of the court. The presence and behaviour of other people: I am particularly stressed by the lawyers of the parties - for the reasons I described earlier [their superior behaviour towards the certified interpreter and formulating linguistically complex sentences to undermine the interpreter's competence or obstruct the interpreting process].

— The courtroom and notary's office as well as the situation of the wedding ceremony, when people are stiff, silent, formal and stressed.

- The unfriendly behaviour of the parties is stressful for me; a negative atmosphere, especially in the courts - the harshness and high expectations of judges and, besides that, jurors who doze off and court reporters who make mistakes; sometimes prolonged interpreting (e.g. in addition to the statement for the police, you have to go for an on-site inspection and interpret there).

Obviously, the certified interpreters' stress has its linguistic and extra-linguistic manifestations which - in many cases - overlap with the exponents of other psycho-affective factors. For example, several certified interpreters mentioned numerous problems which they encounter because of stress, such as omissions, grammatical or lexical errors, equivalence problems or illegible/incomplete notes which they take while listening to the input. Likewise, owing to their experience of stress during court interpreting, the respondents declared that among the non-linguistic aspects which might result from stress are lowered voice quality (e.g. stammering, pauses, voice trembling), body reactions (e.g. dry throat, accelerated pulse, gesticu- 
lation, body tension, sweating, dry mouth, nervous tics, uncontrolled movements) or the organizational aspects of court interpreting (e.g. fiddling with note-taking accessories, chaotic organization of notes), many of which were also declared for other factors.

Generally speaking, stress is one of the more potent psycho-affective factors which may have a negative impact on the quality of court interpreting. The court context itself triggers the experience of stress and, by extension, that of various types of anxiety, and sometimes also of fear. It is, therefore, true that the institutional context of the court, with the imbalance of power and the frequently reported inferior position of the certified interpreter, contributes considerably to subjectively experienced stress.

As has been presented above, in the opinions of the respondents, all of the psycho-affective factors can impact on the way the certified interpreters working in the courtroom render their services. In many cases, this impact is negative and affects the certified interpreters' abilities to produce linguistically correct and equivalent interpretation. What is more, the courtroom settings are also directly linked to the certified interpreters' psycho-affective sequence, in which each component of this sequence can induce another. For instance, the imbalance of power can be a stimulus invoking the interpreter's stress (i.e. a psycho-affective factor) which is then projected onto the interpreter's body tension and dry throat (i.e. bodily reaction), faulty pronunciation, overuse of gestures (i.e. his/her verbal and non-verbal behaviours) and problems with retrieving the input information if not noted down (i.e. cognitive factors). Furthermore, some psycho-affective factors tend to occur together or trigger one another. Such is the case with, for example, lowered selfesteem, anxiety and language ego. A certified interpreter who is unsure of his/her language subcompetence may experience anxiety related to court interpreting and this, in turn, may cause the certified interpreter's language inhibition and his/her limited language performance.

As indicated above, psycho-affective factors can have overlapping or even identical linguistic and extra-linguistic exponents, so it would be perhaps better to speak about the exponents of the interpreter's psycho-affectivity rather than about the exponents of particular factors. It might be so since it is difficult to isolate the exponents for particular factors and the respondents often reported the same manifestations for different factors.

Overall, what results from the findings presented above is that the court is a context which frequently constitutes a rather negative psycho-affective framework for certified interpreters, since they themselves reported that many aspects of certified interpreting in the courtroom contribute to their subjective negative experience of the psycho-affective factors under consideration, of which only three seem to be more facilitative than debilitative (i.e. self-esteem, extroversion, motivation). Thus, it may be concluded that certified interpreting in the courtroom is psycho-affectively demanding and those psycho-affective challenges are not always easy to face. 


\section{Conclusions}

This paper has been an attempt to cast some light on the work of professional interpreters in the courtroom and the psycho-affective framework which it constitutes for certified interpreters. The interpreter's psycho-affectivity, studied within what may be known as interpreter psychology, is a relatively new area of inquiry, with many phenomena still requiring further study. It is constituted by psycho-affective factors, seven of which were examined in this study: anxiety, fear, language inhibition/language ego/language boundaries, extroversion/introversion/ambiversion, self-esteem, motivation and stress. What can be concluded from the study is that many elements of the certified interpreting process taking place in the courtroom are likely to trigger the certified interpreter's experience of psycho-affective factors which then manifests itself in a variety of linguistic and non-linguistic exponents. From the opinions of the respondents, it emerges that only three factors affect the interpreters more positively than negatively (self-esteem, extroversion, motivation) whereas others seem to have an adverse impact on the way the certified interpreters perform in court and, ultimately, on the output.

Finally, the study may bring some practical implications both for interpreting training and for professional practice. Firstly, trainee interpreters should be made aware that their psycho-affectivity is a continually active module of their psychological makeup which may be partially controlled. Thus, next to interpreting and language practice, exercises aimed at developing psycho-affective coping strategies should be included in interpreting training. Moreover, it should also become clear for both trainee interpreters and professional interpreters that interpreting, including court-room interpreting, is a psycho-affectively challenging activity which is hardly perfect and that a seemingly unimportant element of the interpreting process can activate psycho-affective factors which may then affect the output. However, this should not paralyze nor worry interpreters, since interpreting-mediated communication in such sensitive contexts as the courtroom has to be smooth and effective, which does not necessarily mean linguistic and informational flawlessness or perfection.

\section{References}

Arnold, J. and H. D. Brown. 1999. “A map of the terrain.” In: Arnold, J. (ed.). Affect in Language Learning. Cambridge-New York-Melbourne: Cambridge UP, 1-24.

Bontempo, K. and J. Napier. 2011. "Evaluating emotional stability as a predictor of interpreter competence and aptitude for interpreting." Interpreting 13(1). 85-105. https://doi.org/10.1075/ intp.13.1.06bon. 28 Dec. 2019.

Brisau, A., R. Godijns and C. Meuleman. 1994. "Towards a psycholinguistic profile of the interpreter.” Meta: Translators' Journal 39(1). 87-94. 
Cieślik, B. 2016. “Wstęp.” In: Kuźniak, M. Egzamin na Ttumacza Przysięgłego w Praktyce. Język Angielski. Analiza Językowa. Warszawa: C.H. Beck, 1-7.

Colonomos, B. M. 2015. "Integrated Model of Interpreting. Supplemental Notes and Diagrams." Retrieved from http://www.diinstitute.org/wp-content/uploads/2016/03/IMI-SupplementalColonomos-2015.pdf. 12 Nov. 2019.

Coopersmith, S. 1967. Antecedents of Self-Esteem. San Francisco: Freeman \& Co.

Doyle, C. 2003. "Occupational and Organizational Psychology.” In: Bayne, R. and I. Horton (eds.). Applied Psychology. Current Issues and New Directions. London-Thousand Oaks-New Delhi: Sage Publications, 38-52. https://doi.org/10.4135/9781446279151.n3 28 Dec. 2019.

Gorman, P. 2005. Motivation and Emotion. London-New York: Routledge Taylor and Francis Group. Heron, J. 1989. The Facilitator's Book. London: Kogan Page.

Jones, J. M. 2013. Affects as Process. An Inquiry into the Centrality of Affect in Psychological Life. New York-London: Routledge Taylor and Francis Group.

Korpal, P. 2017. Linguistic and psychological indicators of stress in simultaneous interpreting. Poznań: Wydawnictwo Uniwersytetu Adama Mickiewicza w Poznaniu.

Kurz, I. 2003. "Physiological stress during simultaneous interpreting: A comparison of experts and novices." The Interpreters' Newsletter 12. 51-67.

Mead, P. 2002. "Exploring hesitation in consecutive interpreting: An empirical study." In: Garzone, G. and M. Viezzi (eds.). Interpreting in the 21st Century: Challenges and Opportunities. Amsterdam-Philadelphia: John Benjamins Publishing Company, 119-29.

Moser-Mercer, B. 2008. "Skill acquisition in interpreting: A human performance perspective." The Interpreter and Translator Trainer 2(1). 1-28. https://doi.org/10.1080/1750399X.2008.10798764. 28 Dec. 2019.

Piechurska-Kuciel, E. 2008. Language Anxiety in Secondary Grammar School Students. Opole: Wydawnictwo Uniwersytetu Opolskiego.

Riccardi, A. 2015. "Stress.” In: Pöchhacker, F (ed.). Routledge Encyclopedia of Interpreting Studies. London-New York: Routledge Taylor and Francis Group, 405-407.

Sanz, J. 1931. "Le travail et les aptitudes des interprèters parlementaires." Anals d'Orientació Professional 4. 303-18.

Silverman, L. K. (ed.). 1993. Counseling the Gifted and Talented. Denver: Love.

Timarová, Š. and H. Salaets. 2011. "Learning styles, motivation and cognitive flexibility in interpreter training. Self-selection and aptitude.” In: Pöchhacker, F. and M. Liu (eds.). Aptitude for Interpreting. Amsterdam-Philadelphia: John Benjamins Publishing Company, 33-54.

Timarová, Š. and H. Ungoed-Thomas. 2008. "Admission testing for interpreting courses." The Interpreter and Translator Trainer 2(1). 29-46. https://doi.org/10.1080/1750399X.2008.10798765. 28 Dec. 2019.

Valero-Garcés, C. 2005. "Emotional and psychological effects on interpreters in public services. A critical factor to bear in mind." Translation Journal 9(3). Retrieved from http://www.translationjournal.net/journal/33ips.htm. 12 Nov. 2019.

Walczyński, M. 2019. Psycho-affective Factors in Consecutive Interpreting. Berlin: Peter Lang. Zannirato, A. 2013. "The quest for 'perfection." The Interpreter and Translator Trainer 7(1). 10727. https://doi.org/10.1080/13556509.2013.10798846. 28 Dec. 2019. 